Volume 6, Issue 1 (2017) 1-9| Published online 18 October 2017

The publication of the JEOD is supported by the Autonomous Province of Trento, Italy

\section{AUTHOR}

COLIN CAMPBELL

Assist Social Capital CIC, Scotland (UK)

colin@social-capital.net

SILVIA SACCHETTI

Department of Sociology and Social Research,

University of Trento (Italy)

silvia.sacchetti@unitn.it

\title{
Editorial: Community-Based, Collaborative Solutions to Sustainable Economic Development in and around Biosphere Reserves
}

\section{ABSTRACT}

This is the introductory article to the JEOD Special Issue on "Community-Based, Collaborative Solutions to Sustainable Economic Development in and around Biosphere Reserves". In introducing the topic, we make the case for joining the experience of practitioners and scholars in the writing of the issue articles. We outline an institutionalist approach to the study of sustainable development in UNESCO designated Biosphere Reserves (BRs) and highlight how this can help explaining the emergence of a variety of experiences from which practitioners can extract major lessons to solve common problems of collective action within BRs. The editorial concludes by presenting issues for further research.

\section{KEY-WORDS}

BIOSPHERE RESERVES; SOCIAL CAPITAL; SOCIAL ENTERPRISE; COMMUNITY DEVELOPMENT; SUSTAINABLE DEVELOPMENT; OSTROM

\section{Acknowledgments}

The authors wish to thank all the authors, and the anonymous reviewers for the insight they have brought with their comments. Our thanks also go to Barbara Franchini for final editorial advice and Michela Angeli for editing assistance. 


\section{Introduction}

The issue is completely devoted to the topic of community-based, collaborative solutions to the sustainable development of Biosphere Reserves. In interactions with participants in academic and practitioner workshops on sustainable development and social economy organisations, it is quite striking to notice how many scholars and operators appreciate and apply cooperative, community-based frameworks to their work. The idea in the choice of contributions for this Special Issue was to join practice and theory, with the aim of starting a common reflection with practitioners, policy makers and academic researchers on issues that are often addressed without opening appropriate lines of communication between these spheres.

The topic relates closely to the discussions on "Economics in and around Biosphere Reserves" chaired by one of the guest editors, Colin Campbell, at the 4th World Congress of Biosphere Reserves held in Lima, Peru in March 2016. The Lima conference set out a new vision for the Man and Biosphere (MAB) Programme, for the decade 2016-2025, which mainstreams UNESCO Biosphere Reserves as models for national/regional demonstration of sustainable development within national and global agendas for the 2030 Sustainable Development Goals.

Although cooperative, community-based approaches seem to be widespread these days, this has not always been the case. Despite recent popularity, the application of cooperative, community based frameworks to instances of social and natural justice is a relatively recent phenomenon. Only in the mid-1990s, a literature appeared that broadened conceptual tools that, until then, had been polarised between those who favoured state-led regulation and neo-liberal approaches centred on free market. The study of solutions to the management of natural resources took a radical turn after the work of Elinor Ostrom (1990), who identified the conditions under which a "third alternative" is possible. This alternative is based on the ability of individuals to cooperate and to self-organise to establish rules that everyone is asked to respect.

Before these conceptual tools developed, in 1971 UNESCO launched the Man and the Biosphere (MAB) Programme (Ishwaran, Persic and Tri, 2008; Coetzer, Witkowski and Erasmus, 2014). Out of this framework emerged the concept for context-specific conservation (Ishwaran, Persic and Tri, 2008), as well as the World Network of Biosphere Reserves (WNBR) (Ishwaran, 2009). The concept is considered as an international tool for cooperation related to nature conservation, interdisciplinary research and education as well as the basis for developing a sustainable long-term approach for improving the relationship between the environment and the people living within it (Ishwaran, Persic and Tri, 2008; Coetzer, Witkowski and Erasmus, 2014).

In general, the Biosphere Reserve (BR) framework and concept have shifted over time from an initial prioritisation of conservation and research towards the idea of sustainable development where the BR fulfils three main functions: (i) conservation role; (ii) logistic support function; and (iii) development role (UNESCO, 1996; Ishwaran, Persic and Tri, 2008; Coetzer, Witkowski and Erasmus, 2014).

More recently, the Madrid Action Plan (MAP) (UNESCO, 2008) emphasised the role of BRs as "training grounds" (Learning Laboratories - LLabs) to develop sustainable development 
principles translated into local contexts whereby greater local participation and "social learning" are to be integrated (Reed and Massie, 2013) and shared across the World Network of Biosphere Reserves (Ishwaran, Persic and Tri, 2008). As Ishwaran, Persic and Tri advocated (2008, 6): "It is the authors' expectation that the next 5-10 years of experimentation with biosphere reserves as learning laboratories for sustainable development will generate a significant pool of data, information and knowledge about local level practices that give context-specific expression to the global concept of the biosphere reserve".

After about a decade from that statement, we hope that this Special Issue provides some initial indications on the experimental experiences enabled by the UNESCO MAB Programme, with the intent of highlighting the factors that made them more or less successful.

\section{The role of cooperative institutions}

Biosphere Reserves are "commons" at all effects: access cannot be restricted and the use of one individual subtracts to the possibility of another individual to use the resource. Therefore, without a deep knowledge of their nature, and definition of appropriate principles for interaction, the resources produced by the common are overused to the detriment of each and every user. The danger called for by Hardin (1968) in his seminal piece The tragedy of the commons reinstates that resource overuse undermines the resilience of the common, which loses its qualities and ceases to be a resource for the community.

In parallel, institutional economist and political scientists have long studied how shared understanding, cooperation and trust within communities of interests are the pre-conditions for the collective management of commons and their resilience. Specifically, Ostrom (1990) argued in favour of self-defined rules by which the community of users and beneficiaries understand the common advantages of cooperating, and share their sedimented knowledge to define and enforce shared rules for the use of common pool of resources. The scholarly work of Ostrom and colleagues argues against the use and imposition of top-down rules, disconnected from the customs and ability to find commonly beneficial solutions of interested parties. She, in fact, argues that participatory solutions are more promptly respected and enforced.

The conceptual background provided by institutional theory points to one major challenge for policy makers and communities: to endogenously develop a model for the sustainable use of the resources produced by BRs. This implies creating the contextual features and the rules that best serve the development of socio-economic activities (such as sustainable tourism, forestry, waste management, housing, and welfare services) without compromising the ability of the BR system and its population to re-produce and thrive in the long run.

As a reply to this challenge, more recently, Sacchetti and Campbell (2015) have identified (on this Journal) a framework for studying community development. The framework emphasises the role of social enterprise and public engagement in fostering a space of cooperative relations 
amongst communities of interest, which can enhance common welfare. In parallel, the role of social enterprise and public engagement is central in the Social Enterprise \& Biosphere (SEBR) Development Framework applied to BR development and launched by the social enterprise Assist Social Capital in 2013 (ASC, 2013).

Overall, the social enterprise model is growing internationally and "[...] in recent decades the SE [social economy] has not only asserted its ability to make an effective contribution to solving the new social problems, it has also strengthened its position as a necessary institution for stable and sustainable economic growth, matching services to needs, increasing the value of economic activities serving social needs, fairer income and wealth distribution, correcting labour market imbalances and, in short, deepening and strengthening economic democracy" (Chaves and Monzón Campos, 2008: 6).

Likewise, public participation plays a central role in the SEBR Framework, as it supports the emergence of an environment within which enterprises can thrive. There are different levels of participation from the most basic level of information sharing, up to community ownership and participatory democracy. In addition, participation is closely aligned with the idea of social capital (Putnam, 2000; Woolkock, 2001), since it is an effective way to extend networks of trust, so crucial to the flow of information and resources. Overall, participatory approaches are based on the value of engaging and empowering citizens to identify solutions to local issues. Moreover, although solutions are produced locally, they can provide useful lessons for other localities, thus assuming a global relevance. Embedding a culture of participation opens up previously unidentified opportunities for collective action and cooperation. As a result, participation can substantially contribute to the aims of BRs to be learning sites for sustainable development and spaces for experimentation and development of creative ideas.

\section{Experiences from Biosphere Reserves: the role of the UNESCO common institutional framework and of contextual diversity}

Building on this background, the articles published on this Special Issue develop ideas on how the UNESCO MAB Programme, which has institutionalised BRs, has been interpreted at local level, across diverse institutional contexts. Specifically, we are interested in experiences that emphasise the role (and limits) of community-based initiatives, social enterprise and other economy organisations, private business in general, and public participation programmes in enhancing sustainable development in BRs.

The initial article, by Colin Campbell and Silvia Sacchetti highlights the key elements of sustainable social and natural development within the broader institutional umbrella offered by the UNESCO MAB Programme. This article sets out three policy/intellectual frameworks: those supporting BRs, social capital and social enterprises-and the complex relationships between them. The article makes an effective case for systems-based top-down governance being linked 
with bottom-up empowerment to achieve sustainability both for environmental preservation and community economic development. The case presented is in Cat Ba Archipelago Biosphere Reserve. This is one of eight BRs in Vietnam and part of the UNESCO MAB Programme since 2004. These areas are exposed to a serious risk of overexploitation of the natural assets by tourism. The article explores engagement initiatives developed by one of the authors, Colin Campbell, as director of the social enterprise Assist Social Capital. The interest of this experience is that it presents a model for engaging local community constituencies, such as community professions (i.e. farming, fisheries, forestry, and tourism), young people, school students and teachers as well as all seven village Community Learning Centres on Cat Ba Island. In particular, the model implemented by Assist Social Capital, is centred on building social capital and illustrating the opportunities of a social enterprise model in supporting BRs and their communities. The model adopts the OECD's definition of social capital (OECD, 2001), which emphasises cooperation within and among groups by means of networks, shared norms and values, and common understanding. If supporting the emergence of a cooperative relational context was central in the project, equally important was the focus on specific organisational solutions to BR development challenges, namely social enterprises. In the project, these were presented as a sustainable, not-for-private-profit business model achieved through an asset lock, which strives to be financially independent of grants and have primary objectives to achieve social and/or environmental benefit. The efforts to legitimise this social capital/ social enterprise model are shown by documenting the strategy implemented with the project, in the attempt to maintain legitimacy to the eyes of community stakeholders and UNESCO MAB. The insights of this paper demonstrate a potential paradox. On the one hand, a social capital/social enterprise approach requires that actors in the community take organised economic action. On the other hand, such actions must ensure wide stakeholder involvement in the formulation and implementation of activities, to ensure that a common value base is maintained and that activities do not threaten the BR. In this light, the paper provides a framework for analysis, which identifies a plurality of dimensions (physical, relational, policy, organisational), to be considered in synergy when assessing BRs communities and their possibilities. Further research is advocated, to determine whether this model creates a lasting and sustainable environment. In the meantime, the Cat $\mathrm{Ba}$ BR approach was identified as a national example of good practice in combining conservation and development for sustainable development at the United Nations Conference on Sustainable Development (UNCSD) “Rio+20" in 2012.

The third paper by Giovanni Teneggi and Flaviano Zandonai illustrates the case of the Appennino Tosco-Emiliano UNESCO Biosphere Reserve in Italy. Overarching the Tuscany and Emilia Romagna regions of north-central Italy, it covers the Tuscan-Emilian Apennine ridge from Passo della Cisa to Passo delle Forbici, which marks the geographical and climatic boundary between continental and Mediterranean Europe. The area contains nearly 70 per cent of all animal and plant species present in Italy. The main economic activities are tourism, agriculture, artisanship and the processing of high-quality foods. Leisure activities and tourism also represent important economic assets for the 100,000 local inhabitants. The Appennino Tosco-Emiliano BR includes many villages 
that the authors describe as highly enterprising and cooperative. In their case studies, the authors emphasise that the cooperatives that have been set up have revitalised public places by turning private businesses on the verge of closure into productive community businesses. In some instances, local communities have championed short supply chains through networks of local production companies offering products characteristic of the local culture. In others, small social market economy districts encourage business and non-profit organisations. Cultural initiatives re-forge relationships and revitalise intangible resources and strengths introducing a new enterprising spirit and a fresh sense of opportunity. Teneggi and Zandonai also highlight that the Appennino ToscoEmiliano BR most important output is trust, which is created and circulated on a daily basis by the experiences outlined above. The authors describe them as "factories of social cohesion" that keep up the quality of life in the territory. Initiatives that are started by local inhabitants are complemented by people returning to the area or additionally by those from outside the community. The crucial factor ensuring that these activities are productive for the community lies in a social contract to take ownership and responsibility and to make the community a home. Rather than simply inhabiting the area, people who make it their home build deep and long-lasting relationships with the other inhabitants and the place itself. The same holds true for businesses based in the area that incorporate the BR into their production and/or supply chains. This social contract generates a profound sense of relationship that establishes collective destinies. Similar to life in rural and mountain communities in times gone by, people and their families are bound together by similar activities, not merely for the pursuit of profit but through a feeling of shared future. As a result, the authors suggest that enterprising communities rescue neglected physical spaces, making them into sites for living, interacting and working once again. Trust, ownership, relationships and local stakeholders are the assets ensuring protection and competitiveness of the Appennino Tosco-Emiliano BR, which is acting as a model for other rural areas in Italy. The Italian Ministry of Economic Development has selected the area as a model site for further experimentation, with the aim of drawing lessons to be applied in similar localities, and to extending the benefits of community cohesion to other strategic development areas, such as health, education and transport.

Moving to the African continent, the article by Alexio Mbereko, Olga Kupika and Edson Gandiwa explores the evolution of the paradigm adopted by the Zimbabwe Government since the first national park was established, in 1872. They address in particular how biodiversity has been protected by policy initiatives in Middle Zambezi Biosphere Reserve in Zimbabwe, which is part of the UNESCO BR world network since 2010. Research supports the theory that if fauna and flora is not protected by means of rules that are effectively enforced, it degrades at a fast pace (Cf. also Naughton-Treves, Holland and Brandon, 2005). Their findings support the conceptual framework developed by common-pool resource theory, which emphasises that free-riding behaviours can be best avoided by engaging communities of users in the definition and monitoring of rules (Hess and Ostrom, 2003). The authors explain that in the late 1980s, a paradigm shift took place from protection and exclusion to involvement and inclusion of humans in national parks management and the sustainable use of natural resources (Stoll-Kleemann, 
De la Vega-Leinert and Schukltz, 2010). As a result, international conservation initiatives now advocate the use of resource management approaches that centre more on human livelihoods, and BRs are a means to achieve this, under the UNESCO MAB Programme to promote sustainable development based on local community efforts and sound science (Pool-Stanvlie and Clusener-Godt, 2013). However, moving from policy requirements to practice presents obstacles, which the authors analyse taking into account the CAMPFIRE programme (Communal Areas Management Programme for Indigenous Resources), developed within the BR. The main difficulties, as explained, originate from structural weaknesses and national economic difficulties, as well as from the persisting over-exploitation of natural resources, either legally or illegally. Because of these major institutional and economic shortcomings, the authors conclude that CAMPFIRE has not benefitted the poor rural communities of the BR as expected. Looking at perceptions in the community, the authors highlight that community members are aware of the poor level of stakeholder engagement in the programme (citing for example the fact that they are not consulted when hunting licences are granted in the area). Other causes of failure are identified in the support activities for business with a short-term profit motive (game hunting), lack of policy to enable local communities to benefit from the natural resources in the BR, and poor accountability. The outcome is breaking of rules, and emerging of conflict between the local inhabitants and the authorities.

The Swedish approach is illustrated in the article by Magnus Fredricson and Johanna MacTaggart, who shed light on the institutional features of the social economy and how these may offer consistent organisational models for the sustainable development of BRs. The authors apply Flora and Flora (1993) approach to emphasise community development complexity, which is disentangled by identifying different forms of capital: natural, cultural, human, social, political, financial, and in-built capital. The Scandinavian approach aims at addressing all forms of capital holistically and, to do so, it has been applied by activating investments in the development of all forms of capital. The authors describe how the Biosphere Innovation System (BIS) was conceived with such a holistic approach in mind and to enhance social innovation and enable social entrepreneurs to address societal and natural challenges. Especially, the article illustrates what structures have been created to promote and employ innovation for sustainable development in the Lake Vänern Archipelago BR in Sweden, creating an ecosystem that enables use of localised knowledge, participation in social entrepreneurs' forums for discussion, financing and facilitated learning for policy makers and citizens. Being based on shared environmental and social values, the authors highlight how the BIS was created with the policy ambition of enhancing BR sustainability across the globe, by developing a model which could be practically applied to different contexts across the UNESCO BR world network. 


\section{Open research questions}

These contributions emphasise the features of successful and less successful BR experiences. More would need to be uncovered on how these features were brought about. For example, future research could address questions such as (i) what is the role of existing social capital in explaining the success of formal, institutionalised initiatives aimed at increasing cooperative relations? (ii) If existing relational assets have a role, what would the implications be for areas with poor social capital, opportunistic behaviours and short-termism? (iii) What factors enable continuity of BR designated areas? (iv) What is the right mix of top-down and bottom-up initiatives? (v) How can social enterprises and more generally social economy initiatives maintain their pro-social and proenvironmental orientation over time? (vi) What are the limitations of social enterprises in promoting and enabling BR sustainable development?

Further inquiry into the interaction between various institutional spheres, from international to local rules and norms, to social enterprise features, nature of social capital, and BRs geomorphological specificities may originate more refined analytical maps. Understanding social enterprise as being part of wider international and local governance system, underpinned by cooperation and shared pro-social and pro-natural values seem today more and more important, especially in light of the transformations occurring in the role of the state and of the legitimacy crises of major global economic players. More research on the potential of cooperative and community centred initiatives would be needed, especially in contexts where the application of shared values is difficult, that is in systems where besides declaration of intents, the economic, social and political spheres tolerate damaging and unfair rules and practices.

\section{References}

ASC (2013). Social Enterprise \& Biosphere Reserves Development Framework. Edinburgh Scotland, UK: Assist Social Capital CIC. Author: C. Campbell. Available at: http://social-capital.net/wp-content/uploads/2014/03/SEBR-Final.pdf [Accessed: November 2016].

Chaves, R. \& Monzón Campos, J.L. (2008). The social economy in the European Union, CIRIEC Working Paper, No. 2008/02. Available at: http://www.ciriec.ulg.ac.be/wp-content/uploads/2015/11/WP08-02.pdf [Accessed: November 2016].

Coetzer, K.L., Witkowski, E.T.F. \& Erasmus, B.F.N. (2014). Reviewing Biosphere Reserves globally: effective conservation action or bureaucratic label?, Biological Reviews, 89: 82-104. DOI: http://dx.doi.org/10.1111/brv.12044

Flora, C.B. \& Flora, J.L. (1993). Entrepreneurial Social Infrastructure: A Necessary Ingredient. The Annals of the Academy of Social and Political Sciences, 529(1): 48-58.

Hardin, G. (1968). The tragedy of the commons, Science, 162(3859): 1243-1248. DOI: http://dx.doi.org/10.1126/ science.162.3859.1243

Hess, C. \& Ostrom, E. (2003). Ideas, Artifacts, and Facilities: Information as a Common-Pool Resource, Law and Contemporary Problems, 66(1/2): 111-145.

Ishwaran, N. (2009). Editorial. In: UNESCO (Ed). Man and Nature Living in Harmony. The UNESCO Courier, 6: 3. Available at: http://unesdoc.unesco.org/images/0018/001867/186704e.pdf [Accessed: December 2016]. 
Ishwaran, N., Persic, A. \& Tri, N.H. (2008). Concept and practice: the case of UNESCO biosphere reserves, International Journal of Environment and Sustainable Development, 7(2): 118-131. DOI: http://dx.doi.org/10.1504/IJESD.2008.018358

Naughton-Treves, L., Holland, M.B. \& Brandon, K. (2005). The role of protected areas in conserving biodiversity and sustaining local livelihoods, Annual Review of Environment and Resources, 30: 219-252. DOI: https://doi.org/10.1146/ annurev.energy.30.050504.164507

OECD (2001). The Well-Being of Nations, The Role of Human and Social Capital. Paris: OECD Publishing. Available at: http://www.oecd.org/site/worldforum/33703702.pdf [Accessed: January 2017].

Ostrom, E. (1990). Governing the commons. Cambridge: Cambridge University Press. DOI: http://dx.doi.org/10.1017/ CBO9780511807763

Pool-Stanvliet, R. \& Clusener-Godt, M. (Eds.) (2013). AfriIMAB - Biosphere Reserves in Sub-Saharan Africa: Showcasing Sustainable Development. Published by the Department of Environmental Affairs Directorate: Protected Areas Planning, Legislation, Compliance and Monitoring, Pretoria, South Africa and UNESCO Division of Ecological and Earth Sciences, Paris. Available at: [Accessed: February 2017]. http://unesdoc.unesco.org/ images/0022/002269/226919E.pdf

Putnam, R.D. (2000). Bowling Alone: The Collapse and Revival of American Community. New York: Simon and Schuster. DOI: http://dx.doi.org/10.1145/358916.361990

Sacchetti, S. \& Campbell, C. (2015). Creating space for communities: social enterprise and the bright side of social capital, Journal of Entrepreneurial and Organizational Diversity, 3(2): 32-48. DOI: http://dx.doi.org/10.5947/jeod.2014.012

Stoll-Kleemann, S., De la Vega-Leinert, A. \& Schultz, L. (2010). The role of community participation in the effectiveness of UNESCO Biosphere Reserve management: evidence and reflections from two parallel global surveys, Environmental Conservation, 37(03): 227-238. DOI: https://doi.org/10.1017/S037689291000038X

UNESCO (1996). Biosphere reserves: The Seville Strategy and the Statutory Framework of the World Network. Paris: UNESCO. Available at: http://unesdoc.unesco.org/images/0010/001038/103849Eb.pdf [Accessed: January 2017].

UNESCO (2008). Madrid Action Plan for Biosphere Reserves (2008-2013). Paris: UNESCO. Available at: http://unesdoc. unesco.org/images/0016/001633/163301e.pdf [Accessed: January 2017].

Woolcock, M. (2001). The place of social capital in understanding social and economic outcomes. In: F. Helliwell, The contribution of Human and Social Capital to Sustained Economic Growth and well-being. International Symposium Report, Human Resources development Canada (HRDC) and OECD, pp. 65-88. Available at: http://www.oecd. org/innovation/research/1825902.pdf [Accessed: January 2017]. 